\title{
THE EFFECTIVENESS OF MÉZIÈRES THERAPY IN THE ATHLETES WITH LOW BACK PAIN: THE CASE STUDY OF NATIONAL RHYTHMIC GYMNASTICS TEAM OF MURCIA
}

\author{
Orges Lena \\ José Luis Martínez Gil \\ Jasemin Todri \\ Ana Belén Gámez Santiago \\ PhD. Candidate In Health Sciences \\ Catholic University San Antonio of Murcia, Spain \\ E-mail: orges.lena90@gmail.com \\ https://doi.org/10.17060/ijodaep.2017.n1.v4.1051
}

Fecha de Recepción: 3 Marzo 2017

Fecha de Admisión: 1 Abril 2017

\begin{abstract}
Introduction: The Mézières is a postural therapy which consists in improving anatomical postures and mitigation until disappearances of muscular contractures while reducing back pain through the most important muscle recovery by positively contributing in the individuals balance. The combination of this therapy with rhythmic gymnastics results very interesting by demonstrating the balance of posture and training, the modification of exercise type and tries to contribute in the achievement rates for competitions. Methodology:The experimental study was conducted on 35 young athletes of National Rhythmic Gymnastics who train five days per week with a duration of three hours per each session from 50 athletes in total in Sports Palace during a two months period (from 15 November 2016 to 15 January 2017) in the city of Murcia. Precisely, the Mézières therapy was conducted in an experimental group of 20 athletes (from 15 to 30 years old) while other additional data were received from the control group consisted in 15 girls (from 8 to 14 years old) after signing the informed consent from the athletes and their families. The above mentioned therapy was conducted for 2 consecutive months with two weekly individual sessions for each athlete with duration of 30 minutes. The postural evaluation of athletes was done through a meter tape in order to measure the elasticity and muscles tone, the pain scale-VAS while the gymnastics evaluation plan was handled on three dimensions including the dance height and the movement's amplitude. Results: From the realization of pre and post-tests regarding the performance of Mézières therapy it was observed in 15/20 athletes: a reduction of VAS (pain scale) with a minimum of 2 grades; an improvement in the height of the jump by $3 \mathrm{~cm}$; a visible palpable contractures reduction; a postural improvement; a backpack angles improvement; an increase muscles elasticity in lower posterior
\end{abstract}




\section{THE EFFECTIVENESS OF MÉZIÈRES THERAPY IN THE ATHLETES WITH LOW BACK PAIN: THE CASE STUDY OF NATIONAL RHYTHMIC GYMNASTICS TEAM OF MURCIA}

limbs and the realization of a movement amplitude with 20 additional degrees.Discussion:The rhythmic gymnastics is a sport that is practiced on the examined athletes by at least 10 years considering that the smaller accession gymnastics age is 5 years old. While their training is very tough and rigorous as each year the achievement rates are revised by requiring the examination of different sportive recovery and adaptation methods. Conclusions: Consequently for all these reasons the implementation of Mézières therapy in National rhythmic gymnasts of Murcia results fruitful almost being that they emerged sixth in the national competition during last year which confirms that their level of professionalism is very high and a positive prospective can be handled through the exercise of the proposed therapy.

Keywords: Mézières therapy, muscular contractures, posture, rhythmic gymnasts, athletes

\section{ABSTRACT}

Introduction: The Mézières is a postural therapy which consists in improving anatomical postures and mitigation until disappearances of muscular contractures while reducing back pain through the most important muscle recovery by positively contributing in the individuals balance. The combination of this therapy with rhythmic gymnastics results very interesting by demonstrating the balance of posture and training, the modification of exercise type and tries to contribute in the achievement rates for competitions. Methodology:The experimental study was conducted on 35 young athletes of National Rhythmic Gymnastics who train five days per week with a duration of three hours per each session from 50 athletes in total in Sports Palace during a two months period (from 15 November 2016 to 15 January 2017) in the city of Murcia. Precisely, the Mézières therapy was conducted in an experimental group of 20 athletes (from 15 to 30 years old) while other additional data were received from the control group consisted in 15 girls (from 8 to 14 years old) after signing the informed consent from the athletes and their families. The above mentioned therapy was conducted for 2 consecutive months with two weekly individual sessions for each athlete with duration of 30 minutes. The postural evaluation of athletes was done through a meter tape in order to measure the elasticity and muscles tone, the pain scale-VAS while the gymnastics evaluation plan was handled on three dimensions including the dance height and the movement's amplitude. Results: From the realization of pre and post-tests regarding the performance of Mézières therapy it was observed in 15/20 athletes: a reduction of VAS (pain scale) with a minimum of 2 grades; an improvement in the height of the jump by $3 \mathrm{~cm}$; a visible palpable contractures reduction; a postural improvement; a backpack angles improvement; an increase muscles elasticity in lower posterior limbs and the realization of a movement amplitude with 20 additional degrees. Discussion: The rhythmic gymnastics is a sport that is practiced on the examined athletes by at least 10 years considering that the smaller accession gymnastics age is 5 years old. While their training is very tough and rigorous as each year the achievement rates are revised by requiring the examination of different sportive recovery and adaptation methods. Conclusions: Consequently for all these reasons the implementation of Mézières therapy in National rhythmic gymnasts of Murcia results fruitful almost being that they emerged sixth in the national competition during last year which confirms that their level of professionalism is very high and a positive prospective can be handled through the exercise of the proposed therapy.

Keywords: Mézières therapy, muscular contractures, posture, rhythmic gymnasts, athletes

\section{THEORY AND EVIDENCES PERTAINING MEZIERES THERAPY}

The training of the abdominal region has always been a topic of primary interest in the fields of kinesiology and sports science. The importance of this muscularity in the movements of the trunk and in maintaining the stability of the spine as well as its role in the prevention and treatment of 
spinal pathologies has been promoted and developed in a wide variety of studies since 1950 to nowadays.

Among these, the main focus has evolved over the decades, going by the descriptive survey muscle interventions during specific physical analysis of the effects of a training addressed to the muscles of the trunk according to the most varied methods, to the identification of optimal parameters for the achievement of preventive, rehabilitative or conditioned objectives.

Actually, even it has been enabled a knowledge of the biomechanics of the trunk region defining advantages and disadvantages of many analytically investigated exercises, the interest has shifted towards a more global view of the human body in which the specific training of the movement tends to replace the conditioning of the single muscle, in order to achieve the balance of a system where the individual components interact harmonically for the desired function.

The functional center of the body is an important study topic which is developing a real knowledge of "core training" that could revolutionize several training methods assuming a pivotal role in all sectors of the motor activity. Consequently through these apposite surveys remains in focus the enhancement of the link between research in the laboratory and practice in the field, thanks to which the instrumental study of an exercise follows its specific application and induced analysis according to a rational and targeted intervention.

I fact, it is assumed how a strong trunk musculature is able to ensure an effective lumbo - pelvic stability by therefore increasing the capacity of the limbs to develop power as well as improving the neuromotor control. By this way were implemented different practical exercises and a variety of training protocols aimed at a specific conditioning of the "functioning of the body", according to the objectives addressed to "core strength", "core endurance" or "core stability". However, various researches have denied a positive effect in such direction, confirming their usefulness especially for preventive and rehabilitative purposes.

Analyzing the work programs carried out by the athletes in the various studies, lasting from 4 to 8 weeks, emerges that the load modulation is based solely on the volume of work progressions, in particular each researcher has defined a sequence of exercises remained unchanged during the training, only focusing on the rise of sets and reps.

It should be kept in mind that if we want to occupy with the sportive practice it will not be easier to combine the improvement of the tone-tropism of the athlete without stiffen it at the same time. At the same time remains very difficult to achieve high performance in athletes without exposing them to the risk of postural abnormalities, vertebral pain and trauma. For a correct approach to the practice or sports training it should never be lost of sight the guidelines that allow us, effectively, to manage some of these problems related to sport activity.

It is scientifically confirmed that the physical activity and sport have the power to make us more dynamic, efficient, responsive, available to dialogue and socialization, fatigue resistant, more adapt at escape of the trauma and better performing.

Besides to this already important role driven more generally today we recognize another one in healthy prospect who sees and evaluates the beneficial effects of healthy and balanced physical activity, both preventively and compensatory, in the treatment of dystonia morpho -posturali, but contemporary dealing with a pure scientific context the improvement of the cardio circulatory and respiratory condition, in regulating metabolism, the increase of concentration, the slowing down of physical and mental aging process, etc.

This wellness approach to physical activity, which in our western culture comes back after a century of "forgetfulness", initially with an eastern import product such as (Yoga), followed by the francese ones (Mézières, Soucard, B.Bricot, Busquet, deys-Struyf, J. Le Boulch), leads us today to 


\section{THE EFFECTIVENESS OF MÉZIÈRES THERAPY IN THE ATHLETES WITH LOW BACK PAIN: THE CASE STUDY OF NATIONAL RHYTHMIC GYMNASTICS TEAM OF MURCIA}

awareness in sports to also review our athletic training protocols and training, in the light of "new" scientific principles of biomechanics organization of muscle and posturology chains.

With the intensification of the overexposed phenomenon emerged such undetectable information that lead to these conclusions:

- In many sports clubs coaches and the re-educators are not sufficiently prepared or updated. Often deprived of an appropriate academic formation they do not have the knowledge of basic scientific principles, such as those of the correct morphology of bone development, muscle and joint underlying the correct structuring of posture and balance of the muscle chains.

- Unaware, many coaches push their athletes to a practical exasperated in the rhythms and loads, more and more precocious which is not adapted to the biomechanical conditions, development, morphology or psychophysical of subjects;

- The effects of a sports training or rehabilitation path does not always lead to the much-wanted results, both in terms of performance levels and on those of the long-awaited wellbeing. In fact it is not rare that the athletes experience the regression and blocking of their performance because of morpho-postural dystonias developed for the hyper-programming of some muscle chains at the expense of other less involved in the repetition of the specific gesture ;

This is even more serious when the victims are young athletes in the growth phase that are still vulnerable and more prone to micro trauma in the bone-joint growth areas. The stresses, determined by the repetition of efforts and pressures that mainly fatigue the same joints, create much more equal muscle compensations and determine incorrect attitudes and postural imbalances. Starting by the shortening of the whole muscle together, the overall approach aims to identify the greatest number of imbalances and joint pain that result to be subject to prior preventive methodical and careful compensation. This calls into question the exercises that are performed for muscle strengthening. Sometimes it can be an aggravating factor in some of our deviations due to the compensation twists and joint deformations that escape our attention until the pain appears.

In global stretching we keep in mind the following principles enunciated by F. Mezieres:

The tension of the posterior muscles defines in the vertebral column the exaggeration of the sagittal curves and scoliosis.

The lordosis is always primary while kyphosis and scoliosis are secondary deformations.

The lordosis can be modified in the internal rotations and diaphragmatic block in inspiration.

\section{OBJECTIVES}

This research work aims at re-harmonization of the kinetic chains and posture, based on spinal muscular atrophy and global stretching tries to test the effectiveness of this method on sports subjects about:

Harmonization of statics and dynamics muscle chains through stretching and restore of elasticity;

Identification and elimination of postural compensations that hinder the normalization of the static and gestural effectiveness;

Improvement of stability and fluency;

Initiating a re-harmonization of the spine morphology;

Improving the lifestyle with a positive socio-relational and emotional fallout;

Reduction of pain events.

Awareness of the athletes to the self-management of their problem;

Reduction of the importance of individual risk factors;

Planning of preventive measures for a correct approach to sport that does not precede the search results at any cost to the psychological well-being of the subject; 
Research healthy training conditions by applying an appropriate methodology to improve the performance without violating the laws that underlie the posture, to a balanced biomechanics of the muscle chains and an equally balanced physiological development;

The implementation of preventive measures to avoid injuries as well the muscularization which can't often a guarantee the strength and efficiency;

Setting the physical preparation on global as well as on myofascial chains stretching- "taking care to remove the brakes before you even try to get the movements" (Souchard).

\section{PARTICIPANTS}

The experimental study was conducted on 35 young athletes of National Rhythmic Gymnastics who train five days per week with a duration of three hours per each session from 50 athletes in total in Sports Palace during a two months period (from 15 November 2016 to 15 January 2017) in the city of Murcia. Precisely, the Mézières therapy was conducted in an experimental group of 20 athletes (from 15 to 30 years old) while other additional data were received from the control group consisted in 15 girls (from 8 to 14 years old) after signing the informed consent from the athletes and their families. The above mentioned therapy was conducted for 2 consecutive months with two weekly individual sessions for each athlete with duration of 30 minutes.

\section{METHODOLOGY}

The postural evaluation of athletes was done through a meter tape in order to measure the elasticity and muscles tone, the pain scale-VAS while the gymnastics evaluation plan was handled on three dimensions including the dance height and the movement's amplitude. The quantitative statistical analisys was made with SPSS programe.

The analyzed variables are:

Independent variable - Mezieres therapy

Dependent variables as: pain measured with VAS scale (0-5),Jumping, Dance Height, Movement of Flexion- Extension Column Amplitude.

Inclusion criteria: both male and female who practice sports at a competitive level and with a healthy and sporty lifestyle with symptoms and clinical diagnosis of chronic non-specific low back pain and other vertebral pains lasting more than 1 month, diagnosed by the attending physician or specialist.

Exclusion criteria: presence of tumors or spinal metastases, vertebral fractures, severe osteoporosis, bone TB, infection or inflammation in acute diseases with involvement of the central nervous system, severe bronchial asthma, autoimmune disease in active phase, rheumatic diseases in acute stage, herniated discs and lumbar or cervical expelled, pregnant women, people with scoliosis structured with more than $30^{\circ} \mathrm{Cobb}$, insurgent pain lasting for less than 3 months.

\section{RESULTS}

The interval confidence used in the study is $95 \%$.

H1: The effectiveness of Mézières therapy ((variable $\mathrm{M}$ with value 1 (therapy) and 0 (no therapy)) and the previous condition of the athlete (VASB without Mézières therapy) effects positively on his final VAS (VASA variable condition after treatment).

The positive impact of the state of athlete before Mézières therapy and the effect of treatment (demonstrated by the fact that $p$ (in the case of M and VASB) $<0.05$. (Tab.1) 
THE EFFECTIVENESS OF MÉZIÈRES THERAPY IN THE ATHLETES WITH LOW BACK PAIN: THE CASE STUDY OF NATIONAL RHYTHMIC GYMNASTICS TEAM OF MURCIA

Tests of Between-Subjects Effects

\begin{tabular}{|l|r|r|r|r|r|}
\hline Dependent Variable: VASA & \multicolumn{1}{|c|}{$\begin{array}{l}\text { Type III Sum of } \\
\text { Squares }\end{array}$} & df & Mean Square & F & \multicolumn{1}{c|}{ Sig. } \\
\hline Corrected Model & $51.969^{\mathrm{a}}$ & 11 & 4.724 & 9.119 & .000 \\
Intercept & 96.677 & 1 & 96.677 & 186.594 & .000 \\
$\mathrm{M}$ & 10.593 & 1 & 10.593 & 20.445 & .000 \\
VASB & 28.391 & 5 & 5.678 & 10.959 & .000 \\
$\mathrm{M} *$ VASB & 1.065 & 5 & .213 & .411 & .836 \\
Error & 11.917 & 23 & .518 & & \\
Total & 196.000 & 35 & & & \\
Corrected Total & 63.886 & 34 & & & \\
\hline
\end{tabular}

Table 1. a. $\mathrm{R}$ Squared $=.813($ Adjusted R Squared $=.724)$

Statistics also prove that depending on the athlete prior condition and after the treatment with Mézières method his VAS performance increases. (Graph.1)

Graphic 1:

the athlete condition before-after the treatment with Mézières method

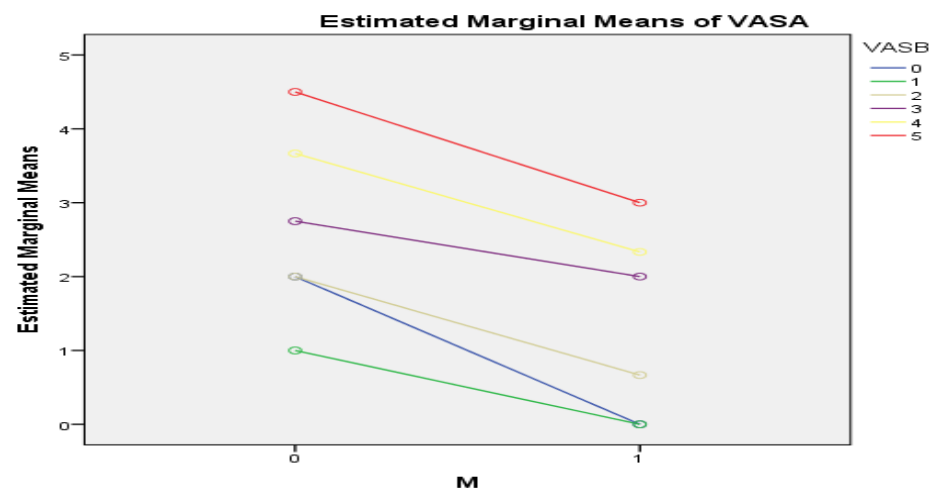

H2: Effect of MEZIERES Therapy ((variable M with value 1 (therapy) and 0 (no therapy)) and the prior situation of the athlete step ( JUMPB without Mézières therapy) impact positively on the performance of its final step ( JUMPA variable in condition after treatment). (Tab.2) 
Tests of Between-Subjects Effects

\begin{tabular}{|c|c|c|c|c|c|c|}
\hline Source & $\begin{array}{c}\text { Type III Sum of } \\
\text { Squares }\end{array}$ & df & Mean Square & $\mathrm{F}$ & Sig. & $\begin{array}{c}\text { Partial Eta } \\
\text { Squared }\end{array}$ \\
\hline Corrected Model & $251.783^{\mathrm{a}}$ & 13 & 19.368 & 8.366 & .000 & .838 \\
\hline Intercept & 6834.248 & 1 & 6834.248 & 2952.058 & .000 & .993 \\
\hline JumpingEvaluationMaterTape & 93.357 & 8 & 11.670 & 5.041 & .001 & .658 \\
\hline MeasurescmBefore (JUMPB) & & & & & & \\
\hline M & 36.151 & 1 & 36.151 & 15.615 & .001 & .426 \\
\hline JumpingEvaluationMaterTape & 3.383 & 4 & .846 & .365 & .831 & .065 \\
\hline MeasurescmBeforeAfterTreat * & & & & & & \\
\hline M & & & & & & \\
\hline Error & 48.617 & 21 & 2.315 & & & \\
\hline Total & 10897.000 & 35 & & & & \\
\hline Corrected Total & 300.400 & 34 & & & & \\
\hline
\end{tabular}

Table.2. a. R Squared $=.838($ Adjusted $\mathrm{R}$ Squared $=.738)$

The positive impact of the state of the athlete step before and after the effect of Mézières treatment (demonstrated by the fact that $p$ (in the case of M and JUMPB) $<0: 05$.

Statistics also prove that depending on the prior condition of the athlete step and treatment with the Mézières therapy his JUMPBA performance increases. (Graph.2)

Graphic 2.

Jumping performance

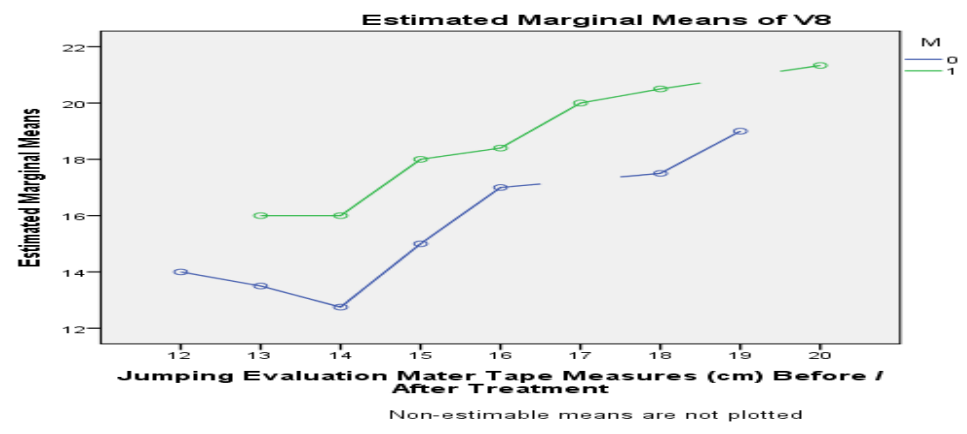

H3: The effect of Mézières therapy(Variable $\mathrm{M}$ with value 1 (therapy)and 0 (no therapy) and prior condition of the athlete dance ( DACB without Mézières therapy) affect positively his performance in the final dance ( DACA the condition of the variable after treatment).

The positive impact of the state of the athlete dance before and after the Mézières therapy treatment (demonstrated by the fact that $p$ (in the case of $M$ and DACB) $<0: 05$.(Tab.3) 
THE EFFECTIVENESS OF MÉZIÈRES THERAPY IN THE ATHLETES WITH LOW BACK PAIN: THE CASE STUDY OF NATIONAL RHYTHMIC GYMNASTICS TEAM OF MURCIA

Tests of Between-Subjects Effects

\begin{tabular}{|l|r|r|r|r|r|}
\hline Dependent Variable: & DACA \\
\hline Source & $\begin{array}{c}\text { Type III Sum of } \\
\text { Squares }\end{array}$ & df & Mean Square & \multicolumn{1}{|c|}{ F } & \multicolumn{1}{c|}{ Sig. } \\
\hline Corrected Model & $344.071^{\mathrm{a}}$ & 13 & 26.467 & 38.332 & .000 \\
Intercept & 8429.037 & 1 & 8429.037 & 12207.571 & .000 \\
DACB & 113.362 & 8 & 14.170 & 20.522 & .000 \\
$\mathrm{M}$ & 67.441 & 1 & 67.441 & 97.673 & .000 \\
DACB * M & 4.706 & 4 & 1.176 & 1.704 & .187 \\
Error & 14.500 & 21 & .690 & & \\
Total & 12430.000 & 35 & & & \\
Corrected Total & 358.571 & 34 & & & \\
\hline
\end{tabular}

Table. 3.a. R Squared $=.960($ Adjusted R Squared $=.935)$

Statistics also prove that depending on the prior condition of the athlete dance and the treatment with the Mézières therapy his dance performance DACA grow. (Graph.3)

Graphic.3.

Dancing performance

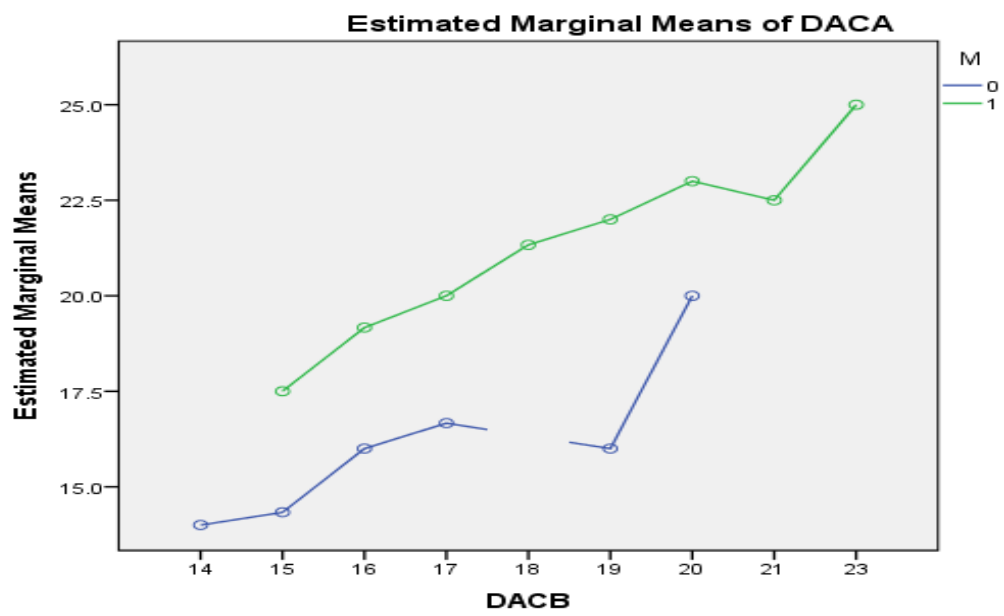

Non-estimable means are not plotted

H4: The effect of MEZIERES Therapy ((variable M with value 1 (therapy)and 0 (no therapy)) and state preliminary amplitude of motion of the sportsman ( MOVB without Mézières therapy) impact positively on the performance of its final movement ( MOVA variable on the situation after treatment).

The positive impact of the state of movement of the athlete before and after the effect of treatment Mézières therapy (demonstrated by the fact that $p$ (in the case of M and MOVB) <0:05. ( Tab.4) 
Tests of Between-Subjects Effects

\begin{tabular}{|l|r|r|r|r|r|r|}
\hline Dependent Variable: & \multicolumn{1}{c|}{ MOVA } \\
\hline Source & $\begin{array}{c}\text { Type III Sum of } \\
\text { Squares }\end{array}$ & df & Mean Square & \multicolumn{1}{c|}{ F } & \multicolumn{1}{c|}{ Sig. } & \multicolumn{1}{c|}{$\begin{array}{c}\text { Partial Eta } \\
\text { Squared }\end{array}$} \\
\hline Corrected Model & $4857.619^{\mathrm{a}}$ & 8 & 607.202 & 14.321 & .000 & .815 \\
Intercept & 41391.655 & 1 & 41391.655 & 976.235 & .000 & .974 \\
M & 855.987 & 1 & 855.987 & 20.189 & .000 & .437 \\
MOVB & 2459.010 & 4 & 614.753 & 14.499 & .000 & .690 \\
M * MOVB & 105.023 & 3 & 35.008 & .826 & .492 & .087 \\
Error & 1102.381 & 26 & 42.399 & & & \\
Total & 67700.000 & 35 & & & & \\
Corrected Total & 5960.000 & 34 & & & & \\
\hline
\end{tabular}

Table 4. a. R Squared $=.815$ (Adjusted R Squared $=.758$ )

Statistics also prove that depending on the prior situation the amplitudes of motion of athlete and treatment with the Mézières therapy his performance of motion MOVA grow (Graph.4.)

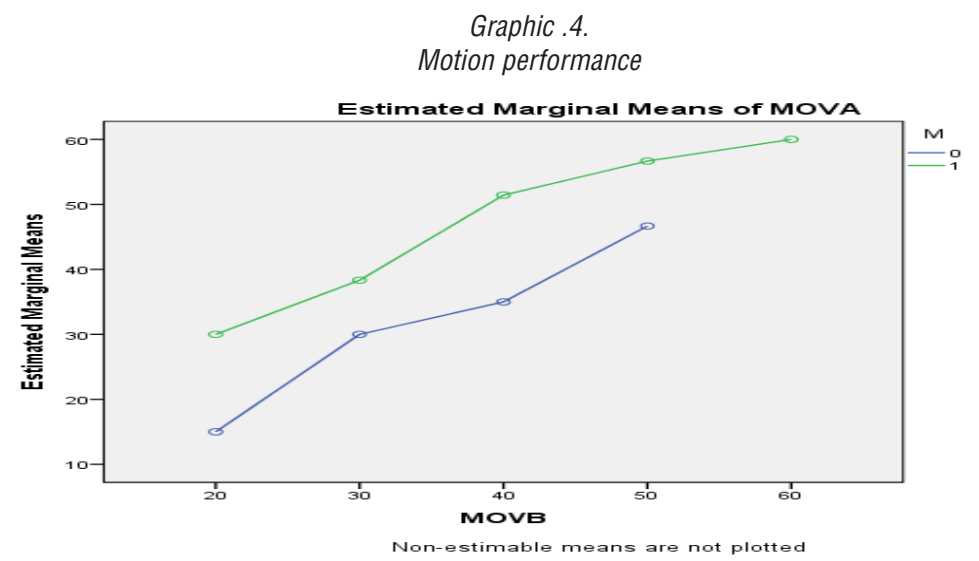

So in any case it is noted that the performance of: VAS, dance, step and movement improved significantly after treatment of the athletes with the method of Mézières.

\section{DISCUSSION S}

Rhythmic gymnastics girls say they have started the sport at age 5 years and have almost 10 years practicing this sport; this makes us find similar characteristics to all the girls by mentioning the gluteal muscles form, thigh muscle, elasticity of adductor and their attitude of posture.

In evaluating the girls in the supine position it is noticed that all the girls stay with feet in plantar flexion.

The posterior musclesof the spine is more evidenced. This is evidenced not only by palpation but also by the measurement of muscular strength with theraband. Posterior musculature difference is about $2 \mathrm{~cm}$. 


\section{THE EFFECTIVENESS OF MÉZIÈRES THERAPY IN THE ATHLETES WITH LOW BACK PAIN: THE CASE STUDY OF NATIONAL RHYTHMIC GYMNASTICS TEAM OF MURCIA}

By the individual consultation is observed that most of the girls turn to rehabilitation sessions only in cases of severe pain or before competitions. If pains persist during the period of they're training, the athlete clearly stated that only one physiotherapy session for them may be necessary so they don't realize the full cycle of rehabilitation causing them to retune to therapist more often in such need.

Physiotherapy session followed by them consists in massage, trigger point therapy, use of machinery such as ultra sound, electro stimulation Tens, infrared and manipulation.

The girls say they have never assist in a proper postural therapy; this doesn't refer to the fact that aren't professional physiotherapists but perhaps in such cases it hasn't been set a proper postural therapy which not only mobilizes but prepares for a new training cycle and also teaches the correct posture.

Referring to tests used and postural evaluations it is noted that back lost physiological curves such as straightening of kyphosis and hyperlordozis.

Elasticity is a characteristic of their body that never lacks; although it brings rapid return to physiological problems after postural rehabilitation therapy. The positioning of feet in plantar flexion in their daily attitude, causes that while positioning their ankles in $90^{\circ}$ makes the entire posterior muscles of the lower limbs to face contractures which obstructs the extension of these posterior kinetic chain.

\section{CONCLUSIONS}

The athletes of rhythmic gymnastics exercises generally are not associated with deep breathing exercises and maybe this affects postural alterations such as fatigue because the muscles of the spine are closely connected to the rib cage muscles.

Also this is an important element that brings thoracic pain all the time which supports the weight and movement of girls; anatomically designed as the most fixed areas of the trunk.

It is noted that the warm-up and stretching are realized only before training, and not after it; this is a very important element for the musculature of the athlete because it affects and prevent immediate painful contractures.

An interesting fact is that the left leg is more resistant than the right leg; this results from the fact that they exercise more on the right leg and left leg support the body weight.

\section{BIBLIOGRAPHY}

Revilla, J. R., \& Moreno, J. R. (2009). Tratamiento global de los desequilibrios sagitales del raquis por el método Mézières. Fisio Global: La revista científica Iberoamericana del método Mézières y terapias globales, (2), 15-23.

Blazevich, A. J. (2006). Effects of physical training and detraining, immobilisation, growth and aging on human fascicle geometry. Sports Medicine, 36(12), 1003-1017.

Coelho, L. (2007). Mezieres' method or the revolution in orthopedic gymnastic. Acta reumatologica portuguesa, 33(3), 372-373.

Gift, A. G. (1989). Visual analogue scales: measurement of subjective phenomena. Nursing research, 38(5), 286-287.

Tsertsvadze, A., Clar, C., Court, R., Clarke, A., Mistry, H., \& Sutcliffe, P. (2014). Cost-effectiveness of manual therapy for the management of musculoskeletal conditions: a systematic review and narrative synthesis of evidence from randomized controlled trials. Journal of manipulative and physiological therapeutics, 37(6), 343-362.

Denys-Struyf, G. (1996). II manuale del mezierista. Vol. 1 e 2. Roma. Marrapese. 
Ridi, R., \& Bongi, S. M. POSTURAL INTEGRATION: Relationship Between Body Posture and Dental Occlusion. Which Evidence of Accuracy in Evaluating.

Mézières, F. (1949). Révolution en gymnastique orthopédique. Paris: Vuibert.

Fratocchi, G., Celletti, C., \& Camerota, F. Muscular stiffness, flexibility and other variations induced in an elite runner by a stretching program performed according to Mezieres Method. Case report.

McGill, S. (2010). Core training: Evidence translating to better performance and injury prevention. Strength \& Conditioning Journal, 32(3), 33-46.

Cordo, P. J., \& Nashner, L. M. (1982). Properties of postural adjustments associated with rapid arm movements. Journal of neurophysiology, 47(2), 287-302.

Gewandter, J. S., Dworkin, R. H., Turk, D. C., Farrar, J. T., Fillingim, R. B., Gilron, I. \& Robinson, J. P. (2015). Research design considerations for chronic pain prevention clinical trials: IMMPACT recommendations. Pain, 156(7), 1184-1197.

Rubinstein, S. M., Terwee, C. B., Assendelft, W. J., de Boer, M. R., \& van Tulder, M. W. (2012). Spinal manipulative therapy for acute low back pain. The Cochrane Library.

McKenzie, R., \& May, S. (1998). La colonna cervicale e toracica: diagnosi e terapia meccanica. Spinal Publications Italia.

Campos, G. E., Luecke, T. J., Wendeln, H. K., Toma, K., Hagerman, F. C., Murray, T. F., ... \& Staron, R. S. (2002). Muscular adaptations in response to three different resistance-training regimens: specificity of repetition maximum training zones. European journal of applied physiology, 88(1), 50-60.

Delecluse, C. (1997). Influence of strength training on sprint running performance. Sports Medicine, 24(3), 147-156.

Marx, J. O., Ratamess, N. A., Nindl, B. C., Gotshalk, L. A., Volek, J. S., Dohi, K. E. I. I. C. H. I. R. O., ... \& Hakkinen, K. E. I. J. 0. (2001). Low-volume circuit versus high-volume periodized resistance training in women. Medicine and science in sports and exercise, 33(4), 635-643.

Häkkinen, K., Newton, R. U., Gordon, S. E., McCormick, M., Volek, J. S., Nindl, B. C., ... \& Humphries, B. J. (1998). Changes in muscle morphology, electromyographic activity, and force production characteristics during progressive strength training in young and older men. The Journals of Gerontology Series A: Biological Sciences and Medical Sciences, 53(6), B415-B423.

Deschenes, M. R., \& Kraemer, W. J. (2002). Performance and physiologic adaptations to resistance training. American Journal of Physical Medicine \& Rehabilitation, 81(11), S3-S16.

Pollock, M. L., Leggett, S. H., Graves, J. E., Jones, A., Fulton, M., \& Cirulli, J. (1989). Effect of resistance training on lumbar extension strength. The American Journal of Sports Medicine, 17(5), 624-629. 
